\title{
Armazém Quinze
}

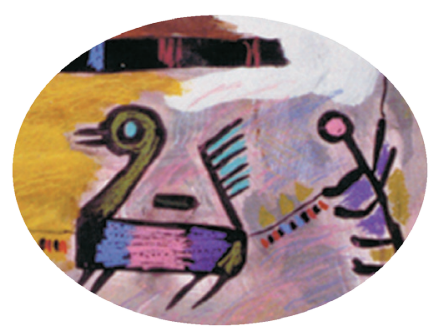

Otoni Mesquita*

\section{Antecedentes}

Em torno de 1669, possivelmente na área ocupada atualmente pelo Armazém 15, foi construída a Fortaleza da Barra do Rio Negro. A primeira construção erigida pelos portugueses, marcando a ocupação do lugar e o princípio de um pequeno aglomerado, composto por indígenas de diferentes nações amazônicas, juntamente com alguns poucos portugueses. O lugar foi denominado de Lugar da Barra do Rio Negro, também conhecida apenas como Barra ou Lugar da Barra. Posteriormente foi elevada à categoria de vila e só muito tempo depois é que foi oficialmente denominada de Manaus.

Quase em frente à fortaleza foi construída a primeira igreja do lugar e posteriormente surgiram um cemitério, o Palácio dos Governadores, um quartel e o Seminário São José. Ainda que insignificante em suas proporções, a área passava a concentrar o primeiro centro administrativo, religioso e militar do povoamento que se organizava.

O desenvolvimento do Lugar da Barra foi muito lento e irregular, tendo apenas um ligeiro crescimento na passagem do século 18 para o 19, quando o governador Lobo d'Almada transferiu de Barcelos para o Lugar da Barra a sede da Capitania de São José do Rio Negro.

Em 1850, quando a região foi elevada à categoria de Província, a vila de Manaus foi promovida à cidade e passou a sediar a capital da Província, ainda que não passasse de um povoado muito pequeno e insignificante, conforme observaram alguns viajantes estrangeiros que passaram pelo lugar naquela

\footnotetext{
* Doutorado em História Social pela Universidade Federal Fluminense, Brasil, 2005. Professor Adjunto da Universidade Federal do Amazonas, Brasil. E-mail: otoni_mesquita@hotmail.com
} 
época. A fortaleza já se encontrava completamente arruinada, entretanto as ilustrações da época mostram que toda aquela região litorânea próxima era amplamente utilizada como uma doca natural.

Mesmo que não apresentasse nenhum equipamento para facilitar o embarque e desembarque de passageiros e de mercadorias, o chamado cais da Imperatriz funcionava como o principal ponto para a entrada e saída da cidade.

Em 1853, ainda sem um porto capaz de facilitar o embarque e desembarque de passageiros e mercadorias, o presidente ${ }^{1}$ da Província anunciava a chegada na Cidade de Barra do primeiro barco a vapor pertencente à Companbia de Navegação e Commercio do Amazonas. Naquele momento, a navegação a vapor assumia uma relevância considerável, sobretudo para toda a região do Amazonas, que se encontrava praticamente isolada do restante do Império brasileiro. Além das grandes dificuldades de comunicação até mesmo entre as províncias mais próximas. Assim, administradores, comerciantes e a população em geral depositavam grandes expectativas no estabelecimento e regularização de uma linha de navegação para Barra.

Durante os primeiros anos da Província o movimento do cais da Imperatriz. era ainda muito lento e pouco controlado, movido praticamente pela entrada e saída dos produtos naturais. Essa produção extrativista chegava a Manaus por meio de pequenas embarcações oriundas dos mais variados rios da região.

Naquele momento, é possível observar que os administradores manifestavam especial atenção no sentido de regularizar o movimento de embarcações, assim como controlar as entradas dos produtos e a cobrança de impostos sobre mercadorias e a comercialização dos produtos na cidade.

Como uma das primeiras tentativas para estabelecer o controle das mercadorias, sobretudo produtos comestíveis comercializados na cidade. Assim, é possível destacar a proposta de criação de uma ribeira dos comestiveis, ${ }^{2}$ feita pela Assembleia Provincial em 1855.

A tal ribeira seria instalada ao lado da rampa de desembarque, localizada na praça da Imperatriz. A iniciativa revela a intenção de promover uma organização e concentração da atividade comercial dos produtos comestíveis que favorecesse maior controle fiscal. Contudo, é somente em 1857 que o presidente João Pedro Vieira ${ }^{3}$ anunciava a construção como a Caz̧a do Mercado.

Em decorrência dos primeiros aterramentos processados na cidade, em meado da década de 1860, iniciava um processo artificial de modificação do 
perfil do litoral da cidade, e o cais da Imperatriz ia sendo pouco a pouco ampliado, avançando um mais sobre o rio Negro e ocupando a área do pequeno igarapé da Ribeira.

Em relatório de 18 de outubro de 1864, o presidente da Província, Adolpho Lacerda, ${ }^{4}$ alegava que na cidade não havia "um ponto decente de desembarque"; portanto, havia orçado o custo de um cais na praça da Imperatriz. Entretanto, os relatórios posteriores não confirmam a realização da obra requerida.

Naquele momento, o aterramento das áreas úmidas e encharcadas era adotado como uma prática profilática recomendada com frequência pela política de saneamento que se difundia através do território nacional, interpretada como medida eficaz no combate às doenças e extinção das infecções.

Em junho de 1866, o presidente da Província, Antônio Epaminondas de Mello, ${ }^{5}$ anunciava que após ouvir o inspetor da Saúde Pública, mandara fazer o aterramento do alargado da praça da Imperatriz, por considerá-lo "prejudicial à salubridade da capital". Segundo ele, as obras se encontravam adiantadas. $\mathrm{Na}$ oportunidade, o presidente reclamava da "imperfeição e má construcção do caes" e reconhecia que tanto o aterro quanto a reconstrução do cais eram obras necessárias e urgentes, sendo elas contratadas com o empreiteiro João Francisco Fernandes.

Em função da lenta burocracia provincial, o contrato para a "feitura de um caes na praça da Imperatriz e seu aterro" foi aprovado somente em 15 de outubro de 1866 pela Lei de n. ${ }^{\circ} 161 .{ }^{6}$ Em abril do mesmo ano, o presidente Epaminondas de $\mathrm{Mello}^{7}$ informava que o aterro da praça da Imperatriz não havia sido concluído.

No ano seguinte, a Lei n. ${ }^{\circ}$ 170, de 15 de julho de 1867, prorrogava por mais seis meses o prazo para a conclusão da referida obra. A falta de materiais e de concorrência para contratação das obras era uma constante em Manaus, resultando um frequente atraso na conclusão das obras e reiteradas reformulações contratuais.

As dificuldades financeiras da Província do Amazonas eram tão restritivas quanto a carência de materiais e a quase total ausência de operários. Tais condições são apontadas com frequência pelos administradores para justificar a falta de qualidade das obras públicas. Em geral, as obras eram construídas com madeira e necessitavam de constante manutenção e reparos. 
Em 1..$^{\circ}$ de junho de 1868 o presidente Jacintho Pereira do Rego ${ }^{8}$ informava que o aterro da praça da Imperatriz fora concluído, ficando o empreiteiro obrigado a conservá-lo durante um ano. Em 18 daquele mesmo mês, foi aprovada a Lei de $n^{\circ} 174$, autorizando a liberação da quantia necessária para a construção de uma rampa no largo da Imperatriz.

Em 1869, poucos anos após a construção do cais, o presidente Wilkens de Mattos $^{9}$ reclamava que não tinham sido respeitadas as condições do respectivo contrato. No ano seguinte o presidente anunciava ter orçado uma planta para a construção de uma rampa que ampliava consideravelmente a área do principal porto da cidade (de 69 para 670). Mattos $^{10}$ justificava que a obra para os serviços de embarque e desembarque da cidade deveria satisfizer as exigências do público.

As atenções com as obras para ampliação da rampa da Imperatriz parecem justificadas pela exigência do movimento da navegação que começava a estabelecer vínculos com praças estrangeiras.

Em março de 1874, o presidente Domingos Peixoto ${ }^{11}$ anunciava o estabelecimento de uma linha de vapor entre a Europa e a capital da Província do Amazonas. A iniciativa partira do comerciante Alexandre Paulo de Brito e o primeiro vapor já partira de Liverpool. O anúncio era dado de uma forma esperançosa afirmando ser o primeiro passo no sentido do engrandecimento e prosperidade do Amazonas, lembrando que o comércio amazonense não teria vida própria enquanto dependesse da praça do Pará.

A expectativa em torno do estabelecimento de uma linha de vapores que colocasse o Amazonas em contato direto com os grandes centros era, sem dúvida, um sonho que embalava muitos administradores locais que acreditavam ser essa a medida capaz de promover a autonomia do Amazonas

Assim, frequentemente são anunciados contratos e possíveis acordos nesse sentido.

Quatro anos depois, o presidente barão de Maracaju ${ }^{12}$ anunciava ter sido inaugurada a linha direta com a chegada do vapor Therezina em 19 de outubro de 1877 , e desde então os empresários vinham mantendo a regularidade do serviço. Contudo, a documentação da época não indica que tenham ocorrido maiores melhoramentos no porto da cidade. 


\section{Histórico}

A partir de 1880, ocorreu uma crescente e rápida valorização da borracha no mercado internacional, provocando um intenso desenvolvimento de uma rede de serviços para atender a sociedade que se instalava com novas aspirações. Entretanto, o embarque e a chegada dos produtos e de passageiros continuavam enfrentando dificuldades para serem executados, provocando grandes prejuízos para os comerciantes e para os cofres do Estado, sobretudo no período da vazante. Essa situação foi mantida até o final do século 19, quando várias tentativas de construir o porto foram frustradas, sobretudo pela intervenção federal, que parecia querer manter a concentração comercial em Belém, evitando que Manaus alcançasse sua autonomia e tivesse como realizar com tranquilidade sua comercialização.

Se por um lado a cidade recebia a borracha, além de outros produtos naturais chegados por meio dos muitos rios amazônicos, que depois eram exportados. O porto se abria a todas as novidades oferecidas pela pretensiosa indústria que representava o mundo do progresso e da modernidade. Importavam-se os mais variados produtos que se encontravam disponíveis pelo comércio, sobretudo europeu e americano.

A partir da documentação oficial, sobretudo os relatórios emitidos pelos presidentes da Província, é possível perceber o crescente movimento do porto de Manaus a partir da década de 1880, quando cresciam também os volumes das obras públicas, demonstrando que já estavam aplicados os excedentes econômicos em melhoramentos urbanos.

As obras do trapiche da Província foram contratadas em 17 de maio de1883, com os empresários Leonardo Antônio Malcher, José Cardoso Ramalho e Manoel Coelho de Castro. No entanto, o contrato foi adiado em 12 de outubro do mesmo ano, garantida a indenização das despesas realizadas. Em 13 de maio de 1884 houve novo adiamento do contrato, ampliado de quarenta para noventa e nove anos os benefícios. Contudo, o presidente Jacob de Niemeyer ${ }^{13}$ informava que, em 7 de novembro de 1887, fora iniciada a obra do Trapiche Princeza Imperial, fora autorizado pela Lei n. ${ }^{\circ}$ 742, de 11 de maio daquele ano e contratada com Ayres Augusto Coelho.

O constante aditamento de contratos, assim como as tentativas de anulação, revela um pouco a disputa de interesses entre os grupos locais. 
Assim, em 2 de junho de 1889, o presidente Joaquim de Oliveira Machado ${ }^{14}$ informava que desde 22 de novembro de 1887 as obras do trapiche estavam "confiadas" aos empreiteiros Malcher, Ramalho \& Castro, o mesmo grupo que fora destituído do contrato, na administração anterior. Notava, entretanto, que a obra caminhava lentamente, sendo fiscalizada pelo chefe da 1. ${ }^{a}$ seção das obras públicas, o engenheiro militar Eduardo Gonçalves Ribeiro.

Em seu relatório de 2 de junho de 1889, o presidente Machado ${ }^{15}$ ressaltava que tanto os projetos quanto os orçamentos dos edifícios da recebedoria; armazém e ponte, fora inicialmente organizados por uma comissão por ele nomeada, mas que sofreram algumas mudanças. Dentre elas, destacava que o contrato inicial previa o uso de alvenaria de pedra e tijolos, no entanto estavam utilizando material de ferro. Contudo, notava que a montagem desse material fora suspensa pelo contratante, desde 15 de maio daquele ano, em razão da falta de pagamento das obras já realizadas e do reduzido número de operários empregados nela.

O prazo de entrega da obra, estabelecido em dezoito meses pelo contrato de 27 de novembro de 1887, fora prorrogado pelo aditamento de 24 de setembro para 30 de setembro de 1889. De 1884 a 30 de abril de 1887, a Província havia empregado $523983 \$ 227$ na referida obra.

O uso de estruturas e mesmo construções de ferro era uma inovação, não somente na Província do Amazonas, mas naquele momento a introdução desse material estava se disseminando em várias regiões do mundo, sendo amplamente aceito.

Esse material composto por placas pré-moldadas e mencionadas pelo historiador Geraldo Gomes da Silva ${ }^{16}$ ao apresentar o seu estudo sobre o armazém do porto de Manaus. O autor afirma não ter encontrado nenhum documento comprovando sua origem, mas analisando suas características formais e sistema construtivo, não duvidou em afirmar que se tratava do sistema Danly, de origem belga.

Ainda que o armazém 15 apresente alguma semelhança formal com os outros armazéns, Silva ${ }^{17}$ indica que os armazéns construídos pela Manáos Harbour Limites são todos de ferro corrugado e tanto as paredes quanto as coberturas foram produzidas pela P\&W. Mac Leillan Ltd - Clutha Works, de Glasgow, de acordo com o registro gravado em algumas estruturas da construção. 
Durante o período provincial, e mesmo nos dez primeiros anos da República, os administradores mencionam obras e reparos de rampas e trapiches no "litoral da cidade"; no entanto, essas obras não superavam definitivamente os velhos problemas, principalmente o período de seca, quando o rio Negro baixava o seu nível sensivelmente, impedindo que os barcos aportassem nas rampas. As obras executadas naquela época não tinham estrutura nem porte para solucionar os problemas de embarque e armazenamento de mercadorias com segurança e eficiência.

Após a proclamação da República, o trapiche passou a se denominado Trapiche 15 de Novembro, sendo oficialmente concluído em 4 de janeiro de 1890, inaugurado juntamente com o prédio do Tesouro Público, na administração do primeiro presidente republicano capitão Augusto Ximennes de Villeroy. ${ }^{18}$ No entanto, antes dessa data, a imagem do Armazém 15 já aparecera virtualmente concluído nos álbuns fotográficos editados pelo Estado do Amazonas, em 1898 e 1899.

Nos primeiros anos da República, durante a rápida permanência do primeiro presidente do Estado do Amazonas Gregório Thaumaturgo de Azevedo, ${ }^{19}$ foi firmado um contrato com o engenheiro civil João Martins da Silva para realizar trabalhos de melhoramentos do porto de Manaus.

Em 1893, o governador Eduardo Ribeiro ${ }^{20}$ renovou o contrato para a construção do porto com o engenheiro civil João Martins da Silva, justificando que traria grandes vantagens para o Estado. $\mathrm{O}$ governador afirmava que o contrato realizaria "uma necessidade palpitante" para a cidade, considerando o modo "lastimavel" com que faziam os trabalhos de carga e descarga do porto. Argumentava ainda que "O serviço publico e particular soffre sempre, além de grandes vexames, atropellos e graves prejuizos".

Ainda que reconhecidas como de extrema importância para o desenvolvimento comercial da cidade, as obras de melhoramentos do porto não foram realizadas durante a administração do governador Eduardo Ribeiro.

Sendo a questão retomada na administração de Fileto Pires Ferreira, ${ }^{21}$ o qual informava que, após a revisão do contrato, o contratante havia se retirado do Amazonas e que só regressara em julho de 1897, trazendo em sua companhia um representante de uma das principais casas da Inglaterra: a Punchard, Mc. Taggart, Lowther.

Naquela oportunidade o engenheiro Martins apresentou os planos 
e o orçamento para a execução das obras, sendo eles aprovados depois de ouvidas as autoridades competentes e feitas as modificações aconselhadas pela Commisão de Saneamento de Manáos, conforme os pareceres de 17 de junho e de 7 de julho de $1897.2^{22}$

$\mathrm{Na}$ oportunidade, o governador confessou que, perante a paralisação da obra contratada com o Sr. Martins e percebendo que o senhor D. Weir, representante da companhia inglesa, estava prestes a se retirar, sem nada resolver, decidiu tratar diretamente com ele no "intuito de levar adiante as referidas obras".

Contudo, as negociações para executar os melhoramentos do porto continuaram a ser feitas de maneira lenta, até, em janeiro de 1898, quando o governador Fileto Ferreira ${ }^{23}$ comunicava ter o comissário do governo federal, Alexandre Sattamini, questionado a competência do Estado em contratar “melhoramentos do porto". Rapidamente a questão tomou grandes proporções e em 5 de fevereiro do mesmo ano foi aprovada a Lei n. ${ }^{\circ} 198,{ }^{24}$ autorizando o governo do Estado a entrar em acordo com o governo federal e o contratante das obras do porto.

Em abril daquele ano, Fileto Ferreira retirou-se para Europa, sendo substituído por seu vice, José Cardoso Ramalho Júnior, ${ }^{25}$ que em julho de 1898 informava que em consequência do questionamento feito pelo comissário Sattamini o governo do Estado foi "convidado" pelo Ministério da Fazenda a rescindir o contrato com o engenheiro Martins, por ter sido considerado "attentatorio dos direitos da União" e caso a recomendação não fosse atendida ameaçava com uma "ação de nullidade". Ainda em julho daquele ano, o Decreto $n .^{\circ} 257^{26}$ autorizava a abertura do crédito necessário para indenizar o engenheiro João Martins da Silva pela rescisão do contrato.

Em julho de 1899 o governador Ramalho Júnior ${ }^{27}$ comunicava que a questão já se debatia há muito tempo, "sem ainda haver tido a sua necessaria solução"; enquanto isso, Manaus continuava sofrendo as deficiências do serviço do porto. Em setembro do mesmo ano, a Lei n..$^{\circ} 28128$ autorizava o Poder Executivo a entrar em acordo com o governo federal "no intuito de levar a effeito as projectadas obras de melhoramentos do porto de Manáos".

A falta de um porto amplo e moderno na capital do Amazonas comprometeu por muitos anos a economia da região. Dentre as constantes lamentações governamentais repetiu-se por muitos anos a falta de condições 
nos serviços de embarque e desembarque de mercadorias em Manaus, cujo sistema era rudimentar e muito deficiente, pois a cidade não dispunha de um porto devidamente equipado, recorrendo-se com frequência ao porto de Belém para escoar grande parte da produção extrativa que era exportada. Essa situação, além de produzir grandes prejuízos ao comércio local, afetava também a receita do cofre estadual.

Em 1904, o ex-senador Lopes Gonçalves ${ }^{29}$ afirmou que o contrato para a construção do porto da cidade de Manaus foi "celebrado" em 1. de agosto de 1900, com Bromistau Rymkiewicz, que organizara uma companhia, na Inglaterra e no Brasil, denominando-a Manáos Harbour Limited. Os trabalhos de construção foram iniciados em julho de 1902 e em maio de 1903 já haviam construído um cais com quatro trapiches e estava concluída a colocação de um grande flutuante com três torres movidas por eletricidade.

No mesmo ano da publicação de Gonçalves passaram por Manaus Godinho e Lindemberg ${ }^{30}$ que, ao discorrer sobre o porto da cidade, afirmavam que a obra fora contratada com o barão Rienckievicz, engenheiro construtor das obras da serra do Cubatão, auxiliado pelo Dr. Álvaro de Carvalho, que talvez fosse seu sócio. No entanto, a americana Marie Wright ${ }^{31}$ informava, em 1907, que o contrato para o melhoramento do porto foi feito com a firma inglesa Manáos Harbour Company Limited e as docas foram planejadas e praticamente construídas sob a direção do engenheiro cubano A. de Lavandeyra, sendo os trabalhos iniciados em 1902. Contudo, Luiz de Miranda Corrêa ${ }^{32}$ acrescenta essa informação, que Antônio Lavandeira projetara o porto, juntamente com o Dr. Cavalcanti de Albuquerque, "sobre as ideias deste último".

Em 22 de agosto de 1902 foi sancionada a Lei n. ${ }^{\circ}$ 384,,33 aprovando o contrato de 25 de março do mesmo ano, ampliando para sessenta anos o prazo de concessão dos serviços do Trapiche 15 de Novembro para a Empreza de Melhoramentos do Porto de Manáos.

O porto de Manaus, com sua ponte flutuante em forma de T, é conhecido como Road-way, denominação legada pelos ingleses. Essa ponte tem cerca de duzentos metros de comprimento e cerca de vinte de largura. Apresenta laterais para uso de pedestre e uma pista central para veículos. Há alguns essa ponte foi avariada por uma grande embarcação, mas foi recuperada. Nas proximidades dessa ponte flutuante existe uma outra com uma estrutura bastante semelhante, além de outras de menores proporções. Todo esse conjunto flutuante, assim 
como os prédios que abrigavam a administração do porto, foi tombado pelo Patrimônio Histórico.

No movimento do porto se anunciava a efervescência que caracterizava a cidade em seus áureos tempos. Mas foi também a redução do movimento portuário um dos primeiros indícios da perda do monopólio da borracha e da crise imanente. O colapso se manifestou de forma crucial paralisando bruscamente todo o movimento comercial, que por um curto período instalara, animara e alimentara toda a estrutura de uma sociedade burguesa e consumista.

Em cinco décadas o movimento do porto se tornou comedido e aparentemente estabilizado, do ponto de vista da economia local, bem de acordo com o ritmo da sociedade que resistiu, estabeleceu e conviveu com suas tradições. A localização do porto se encontra em uma área tradicional, não somente do ponto de vista histórico, mas de uso da população. São os mais variados segmentos e classes da sociedade local, que se diversificam com a variedade de atividades ali exercidas, nas mais variadas condições e turnos.

Entretanto, em 1967, com a implantação da Zona Franca de Manaus, iniciava-se uma política que pretendia animar e integrar a região. A entrada dos mais variados produtos importados animava o comércio local e atraía grandes levas de turistas, mas foi somente duas décadas depois que o Distrito Industrial de Manaus passou a apresentar uma produção que justificava os investimentos.

Até a última década do século 20, os diversos armazéns do porto preservavam sua função inicial para o qual foram construídos, ou seja, armazenar a carga de entrada e saída. Entretanto, com as mudanças promovidas pelos sistemas de transportes de mercadorias, os contêineres de grandes formatos passaram a ser utilizados por garantir maior segurança e dispensar a guarda em armazéns, gerando assim a perda da função das referidas construções, em praticamente todos os portos.

Nos últimos anos do século 20, parte do porto de embarque sofreu reformas, definindo novas funções para alguns de seus armazéns. Atualmente a estação de embarque se encontra ampliada e bastante movimentada. Grande parte da movimentação se encontra vinculada aos serviços de bares e lanches que ocupam predominantemente o lugar, com suas mesas e música em alto volume. 
Parte do espaço utilizado para o serviço de vendas de passagem e alguns serviços públicos, outra parte ocupada por algumas pequenas lojas de souvenir e outros materiais, além da marcante ocupação dos bares com música ao vivo ruidosa, frequência predominantemente popular, bastante animada e com rotatividade intensa.

O movimento popular ficou mais intenso em virtude da tentativa de organização e controle do serviço de embarque e desembarque de passageiros que utilizam as pequenas embarcações que realizam curtos trajetos na área em entorno de Manaus. Contudo, são os mesmos espaços e serviços oferecidos aos transatlânticos e aos turistas dos grandes cruzeiros que aportam em Manaus.

Cidades como Belém e Rio de Janeiro já foram agraciadas com variados projetos para os novos usos desses espaços. Em Belém, as docas se tornaram um espaço de referência, enquanto que no Rio de Janeiro os projetos ainda não foram devidamente efetivados como um todo.

\section{Contextualização}

O Armazém 15 é uma das mais antigas construções que integram o complexo do porto de Manaus, tombado em 1987, juntamente com as outras edificações que compõem o conjunto que se encontra distribuído pela área de ocupação mais antiga da cidade de Manaus. Exatamente no ponto onde foi iniciada a ocupação do lugar. Portanto, a área histórica mais relevante da cidade.

Ainda que seja apenas um armazém em ferro, com a aparência singela de um galpão, trata-se de um relevante exemplar da arquitetura de ferro no Brasil, não somente por ser uma das primeiras construções no gênero. Mas pelo significado assumido para a história da arquitetura e do comércio local, sendo um modelo relevante entre as obras das construções de ferro mais antigas no Brasil.

Trata-se de uma edificação singela do ponto de vista de uma análise formal mais exigente, pois as suas linhas estruturais e seu desenho arquitetônico se encontram intimamente comprometidos com a função utilitária do projeto, ou seja, a armazenagem de mercadorias. Entretanto, constitui-se num raro exemplar das novas soluções construtivas apresentadas pela indústria naquele momento histórico. 
Ainda que formalmente a construção se revele bastante simplificada em sua configuração mais geral e estrutural, não deixa de revelar forte compromisso com a arquitetura e a estética tradicional. Além de sua resistência material, pode-se ressaltar o aspecto decorativo e arquitetural das placas, que mesmo destituída de qualquer recurso cromático, apresentam uma dinâmica animada pelas superfícies côncavas e convexas.

A junção das placas resulta em uma solução formal que remete diretamente à técnica da bossagem renascentista, revelando, portanto, um claro comprometimento com a arquitetura clássica. Além disso, o uso das envasaduras em arco batidos apresenta uma ordem e variação que sugerem a existência de um projeto com preocupação estética.

Não se pode destituir a importância dessa obra, tanto do ponto de vista arquitetônico (da história da arquitetura de ferro e da indústria) quanto de sua significação para a história da cidade (história da arquitetura, do porto e do comércio local). Além disso, trata-se de um raro exemplar da história da indústria.

Pesquisas diversas não conseguiram localizar documentos que confirmassem com precisão a procedência do material do Armazém 15, contudo a análise da aparência formal dos variados elementos que constituem a obra, assim como o estudo comparativo das soluções técnicas e construtivas adotadas levaram o historiador Geraldo Gomes da Silva ${ }^{34}$ a apontar grandes similaridades com a produção apresentada como sistema Danly.

Segundo o historiador Geraldo Gomes da Silva, ${ }^{35}$ o sistema Danly foi desenvolvido pela Forges D'Aiuseau, fundição belga, uma das primeiras a desenvolverem a técnica de construções a partir de placas galvanizadas, uma importante inovação técnica da indústria capaz de solucionar, ao mesmo tempo, "o problema técnico do isolamento térmico das habitações metálicas, como para o problema estético gerado pelas tentativas industriais anteriores, no que se refere à vedação dos edifícios anteriores". O sistema foi patenteado por Joseph Danly e se tornou conhecido no final do século 19, passando a disputar o mercado internacional, juntamente com a produção inglesa e escocesa.

Trata-se de uma obra de grande valor histórico para a cidade, um marco simbólico não somente como um monumento representativo da situação de prosperidade que caracterizou a economia baseada da borracha. Além disso, o armazém se constitui num território de grande significação social, quer pelo 
papel desempenhado como a principal porta da cidade, por onde transitavam passageiros, operários, comerciantes e mercadorias, quer pelo capital simbólico assumido através de várias décadas de convivência e história.

A proximidade da Igreja Matriz, o intenso movimento produzido pelo principal terminal de ônibus da cidade, carregado de estudantes, comerciários e desempregados; bares e botecos baratos, bancas de comida expostas pela rua; a grande feira de camelôs se espalha por toda a redondeza e sufoca os monumentos, o ritmo dos transeuntes e a animação dos pequenos e dos grandes comércios que se modificam para permanecer na área; o movimento dos bares, às vezes vazios, outras repletos por trabalhadores, vagabundos e pedintes atraídos pela animação triste da zona de prostituição mais antiga da cidade e cujos domínios já ocupa áreas internas do porto.

\section{Notas}

${ }^{1}$ Relatório do vice-presidente Corrêa de Miranda, de 9 de maio de 1853, p. 5.

2 Annaes da Assembleia Legislativa Provincial do Amazonas do biênio 1854/1855. Manáos: Typographia do Amazonas, 1881, Seção de 21 de maio de 1855, p. 51.

3 Exposição do pres. Dr. João Pedro Dias Vieira em 26 de janeiro de 1857. Manáos: Typ. Francisco José da Silva Ramos. 1857, p. 17.

${ }^{4}$ Relatório de 18 de outubro de 1864, do presidente da Província, Adolpho Lacerda, p. 28-29.

${ }^{5}$ Relatório de 24 de junho de 1866, do presidente da Província, Antônio Epaminondas de

${ }^{6}$ Coleção de Leis da Província do Amazonas.

${ }^{7}$ Exposição de 30 de abril de 1867 do presidente Antônio Epaminondas de Mello.

${ }^{8}$ Relatório do presidente Dr. Jacintho Pereira do Rego, em 1. ${ }^{\circ}$ de junho de 1868.

${ }^{9}$ Relatório do presidente Wilkens de Mattos, em 4 de abril de 1869. Manáos: Typografia do Amazonas, 1869, p. 36.

${ }^{10}$ Relatório do presidente Wilkens de Mattos, em 25 de março de 1870. Manáos: Typographia do Amazonas, 1870, p. 21.

${ }^{11}$ Falla do pres. Domingos Monteiro Peixoto, em 25 de março de 1874, p. 58.

${ }^{12}$ Falla de 25 de agosto de 1878 do presidente da Província do Amazonas, barão de Maracaju, p. 58. 
${ }^{13}$ Exposição do presidente coronel Conrado Jacob de Niemeyer, em 10 de janeiro de 1888. Manáos: Typographia do Amazonas, 1888.

${ }^{14}$ Relatório do presidente Joaquim de Oliveira Machado, em 2 de junho de 1889. Manáos: Typographia do Comercio do Amazonas, 1889, p. 41.

${ }^{15}$ Relatório do presidente Joaquim de Oliveira Machado, em 2 de junho de 1889. Manáos: Typographia do Comercio do Amazonas, 1889, p. 42.

${ }^{16}$ SILVA, Geraldo Gomes da. 1987, p. 201.

${ }^{17}$ Idem.

18 SOUZA, Antônio Monteiro. Amazônica. História e administradores do Amazonas. Manaus. Ed. Gov. do Estado do Amazonas, 1966, p. 71.

${ }^{19}$ Mensagem do presidente do Estado do Amazonas, Gregório Thamaturgo de Azevedo, em 15 de setembro de 1891.

${ }^{20}$ Mensagem do governador Eduardo Ribeiro, em 10 de julho de 1893, p. 7.

21 FERREIRA, Fileto Pires. A verdade sobre o caso do Amazonas. Rio de Janeiro: Typographia do Jornal do Commercio, 1900, p. 85.

${ }^{22}$ Idem.

${ }^{23}$ Mensagem de 6 de janeiro de 1898, apresentada pelo governador Fileto Ferreira, p. 36.

${ }^{24}$ Colleção de Leis - 1897-1899, 1902, p. 30.

${ }^{25}$ Mensagem apresentada pelo governador José Cardoso Ramalho Júnior, em 10 de julho de 1898 , p. 5.

${ }^{26}$ FERREIRA, Fileto Pires. A verdade sobre o caso do Amazonas. Rio de Janeiro: Typographia do Jornal do Commercio, 1900, p. 106.

${ }^{27}$ Mensagem de 10 de julho de 1899, apresentada pelo governador Ramalho Júnior, 1899, p. 24.

${ }^{28}$ Colleção de Leis do Amazonas - 1897-1899, 1902, p. 88.

${ }^{29}$ GONÇALVES, Augusto César Lopes. O Amazonas: esboço histórico, chorográphico e estatístico até o ano de 1903. New York: H. J. Hanf, 1904, p. 60.

${ }^{30}$ GODINHO, Victor e LINDENBERG, Adolpho. Norte do Brasil. Rio de Janeiro: Laemert \& Cia., 1906, p. 54.

${ }^{31}$ WRITNG, Marie Robson. The New Brazil. Philadelphia: George Barrie \& Son, 1907, p. 394. 
${ }^{32}$ CORRÊA, Luiz de Miranda. Porto de Manaus. In. Arquitetura, revista do IAB. Guanabara, dezembro de 1965, n.o 42, 1965, p. 45.

${ }^{33}$ Colleção de Leis do Amazonas, 1903, p. 16.

${ }^{34}$ SILVA, Geraldo Gomes. Arquitetura de Ferro no Brasil. São Paulo: Nobel, 1987.

35 SILVA, Geraldo Gomes. Arquitetura de Ferro no Brasil. São Paulo: Nobel, 1987.

\section{Referências}

CORRÊA, Luiz de Miranda. Porto de Manaus. In: Arquitetura, revista do IAB, Guanabara, dezembro de 1965, n. ${ }^{\circ}, 42,1965$.

FERREIRA, Fileto Pires. A verdade sobre o caso do Amazonas. Rio de Janeiro: Typographia do Commercio, 1900.

GODINHO, Victor; LINDENBERG, Adolpho. Norte do Brasil. Rio de Janeiro: Laemert \& Cia., 1906.

GONÇALVES, Augusto César Lopes. O Amaz̧onas: esboço histórico, chorográphico e estatístico até o ano de 1903. New York: H. J. Hanf, 1904.

SILVA, Geraldo Gomes da. Arquitetura de Ferro no Brasil. São Paulo: Nobel, 1987.

SOUZA, Antônio Monteiro de. Amazônia - história e administradores do Amazonas. Manaus: Ed. Gov. do Estado do Amazonas, 1966.

WRITNG, Marie Robson. The New Brazil. Philadelphia: George Barrie \& Son, 1907.

\section{Documentos Oficiais}

Annaes da Assembléa Legislativa Provincial do Amazonas do Biennio 1854/1855. Manáos: Typographia do Amazonas, 1881.

Colleção de Leis do Amazonas - 1897-1899. Manáos: Typographia Palais Royal, 1902. 


\section{Relatórios, Exposições, Fallas e Mensagens}

AZEVEDO, Gregório Thaumaturgo de. Mensagem lida perante o Congresso Amazonense, na sessão de 25 de novembro de 1891. Manáos: Typographia do Commercio do Amazonas, 1891.

MARACAJU, barão de. Falla do presidente da Provincia do Amazonas em 25 de agosto de 1878. Manáos: Typographia do Amazonas, 1878.

FERREIRA, Fileto Pires. Mensagem do governador em 6 de janeiro de 1898. Manáos: Typographia do Diário Official, 1898.

LACERDA, Adolpho de Barros Cavalcanti de Albuquerque. Relatório do presidente da Provincia do Amazonas em 18 de outubro de 1864. Pernambuco: Typographia de Manoel Farias Filho, 1864.

MATTOS, José Wilkens de. Relatório do presidente da Provincia, em 25 de março de 1870. Manáos: Typographia do Amazonas, 1870.

. Relatório do presidente em 4 de abril de 1869. Manáos: Typografia do Amazonas, 1869.

MELLO, Antônio Epaminondas de. Relatório do presidente da Provincia do Amaronas em 24 de junho de 1866. Recife: Typographia do Jornal do Recife, 1866.

MIRANDA, Corrêa de. Relatório do vice-presidente da Provincia do Amazonas em 9 de maio de 1853. Capital do Amazonas: Typographia de Manoel Silva Ramos, 1853.

NIEMEYER, Conrado Jacob de. Exposição do presidente da Província do Amazonas em 10 de janeiro de 1888. Manáos: Typographia do Amazonas, 1888.

OLIVEIRA MACHADO, Joaquim. Relatório do presidente da Provincia do Amazonas, em 2 de junho de 1889. Manáos: Typographia do Commercio do Amazonas, 1889.

PEIXOTO, Domingos Monteiro. Falla do presidente da Provincia do Amazonas em 25 de março de 1874. Manáos: Typographia do Commercio do Amazonas, 1874.

RAMALHO Júnior, José. Mensagem do governador do Estado do Amazonas, emitida 
em 10 de julho de 1899. Manáos: Imprensa Official, 1899.

RAMALHO JÚNIOR, José. Mensagem emitida em 10 de julho de 1898. Manáos: Imprensa Official, 1898.

REGO, Jacintho Pereira do. Relatório do presidente da Provincia do Amazonas em 1. de junho de 1868. Manáos: Typographia do Amazonas, 1868.

RIBEIRO, Eduardo Gonçalves. Mensagem do governador, em 10 de julho de 1893. Manáos: Typographia do Diário Official, 1893.

VIEIRA, João Pedro Dias. Exposição do presidente da Provincia do Amazonas em 26 de janeiro de 1857. Manáos: Typographia Francisco José da Silva Ramos, 1857. 